\title{
Tourism Cluster Competitiveness and Sustainability: Proposal for a Systemic Model to Measure the Impact of Tourism on Local Development
}

\author{
Sieglinde Kindl da Cunha* \\ E-mail address: scunha@brturbo.com.br \\ Universidade Federal do Paraná \\ Curitiba, PR, Brazil
}

João Carlos da Cunha

E-mail address: jccunha@ufpr.br

Universidade Federal do Paraná

Curitiba, PR, Brazil

\begin{abstract}
This article proposes a model to measure tourism cluster impact on local development with a view to assessing tourism cluster interaction, competitiveness and sustainability impacts on the economy, society and the environment. The theoretical basis for this model is founded on cluster concept and typology adapting and integrating the systemic competitiveness and sustainability concepts within economic, social, cultural, environmental and political dimensions. The proposed model shows a holistic, multidisciplinary and multi-sector view of local development brought back through a systemic approach to the concepts of competitiveness, social equity and sustainability. Its results make possible strategic guidance to agents responsible for public sector tourism policies, as well as the strategies for competitiveness, competition, cooperation and sustainability in private companies and institutions.
\end{abstract}

Key words: tourism; cluster; local development; competitiveness; sustainability.

Copyright (C) 2005 Brazilian Administration Review. All rights reserved, including rights for translation. Parts of this work may be quoted without prior knowledge on the condition that the source is identified.

* Corresponding author: Sieglinde Kindl da Cunha

Universidade Federal do Paraná, Departamento de Administração, Av. Pref. Lothário Meissner, 632, Jardim Botânico, 80210-170, Curitiba, PR, Brazil. 


\section{INTRODUCTION}

Over the last fifty years, tourism has been one of the activities with the highest potential for expansion in the world. Since the 1980s, the quickening internationalization process and the opening of national economies have boosted tourism to becoming the second most global sector, second only to the financial sectors (Silveira, 2002). Improved transport and communications systems that have reduced traveling time and costs, as well as the increasing number of business trips and social gains, such as paid holidays and long weekends, have accelerated the growth of tourism and the internationalization process.

Owing to its potential for growth and due to the fact that it is a product that can only be consumed in loco, tourism takes on an important role as a strategy for local development. According to the World Tourism Organization (WTO, 2004), tourism is a sector that favors local development because it generates jobs, increases the income of workers and stimulates capital investments through new business opportunities, which results in the establishment of new organizations, including SME, among other advantages. The development of tourism can also bring many negative impacts to the economic, social and environmental sustainability of the local community, such as noise, water and visual pollution, invasion of protected areas, property speculation, increased violence, loss of local identity and culture, modification of consumer patterns etc.

The direction and intensity of the impact (be it positive, negative or both) depend on the way local social actors are organized and interact to achieve common goals concerning improved local standards of living, broadened attractions and competitiveness and the protection and preservation of the cultural and natural environment. Even with tourism's potential for development at all levels, there have been very few studies concerning models for evaluating the local impact of tourism.

The best-known models for measuring this impact are those that evaluate the local economic impact on jobs and revenues, but very few evaluate the positive or negative influence that tourism has on an area and its population and their economic, social-cultural and environmental aspects in a systemic way.

The characteristics of tourism activity, besides being strongly linked to physical space (territory) and abstract space (interactions among local and social actors) is closely linked to culture and the preservation of nature, since it should be used without being destroyed.

While industry destroys to produce, tourism should preserve to produce. Harmonizing tourism with the environment is a change in the way of thinking, a concept innovation to overcome and opposition that easily happens between destructive tourism and the protection of an environment that must be preserved. (Ruschmann, 2001, p. 69)

The concept of cluster is suited to specific characteristics of tourism activities. The tourism product interacts with local base (physical space and social actors), leading to joint actions of inter-related enterprises with great power to create conglomerates. Furthermore, other characteristics define the cluster potential of tourism activities: the complementarities and interdependence among the parts of a tourism conglomerate occur through the interaction and organization of the local actors; the necessary integration of culture, economy and nature results in actions and interventions which come true in a systemic way, and the power of attraction depends on the differing potential of the tourism product and the supporting services.

The central hypothesis of the formulation of the evaluation model of tourism impact in local development proposed in this article is that tourism activity should be one of the main sources of sustainable regional development, with positive effects on the creation of jobs, the generation of income and improvements in the quality of local life. Meanwhile, sustainable development requires actions as a means of reducing destructive pressures on the environment, cultural integrity and the 
quality of life of the local population. The actions and integrated creation of tourism's sustainable development must be based on studies that evaluate the positive and negative impact of the activity, with the economic, socio-cultural and environmental variables dimensioned in a systemic way.

This article aims to present a proposal to measure the impact of tourism on local development by way of cluster analysis. A systemic model is proposed to measure the variables that favor the degree of complementarities and interaction among local social actors, the competitiveness of the tourism cluster considering its meta, meso, macro and micro economic aspects and its sustainable economic, social cultural and environmental potential.

To achieve this goal, the article will be developed by presenting a theoretical foundation used in the development of the impact model, a criticism of the current models and the presentation of the impact model measure suggested by the author. Firstly, it outlines the local development concept, the characteristics of tourism and its capability of influencing local development. Secondly, the relevance of the conceptual referential of clusters is examined (Porter, 1999) along with the tendency of tourism activities towards clustering. From this referential, the complementary relations of a tourism product are highlighted in addition to the competitive-cooperative strategies that are developed among the social actors, the explanatory adherence of the variables that make up a tourism cluster (complementarities, cooperation and competition and its capacity to ease or intensify the tendency towards the concentration and appropriation of sectorial, social and spatial concentration. Second Section outlines the theoretical competitiveness referential on the systemic focus, approaching the concepts and the variables at the meta, meso, macro and micro economic levels. Third Section presents the relevance of dealing with environmental, cultural, social and economic sustainability on the evaluations of the impact of the activity of tourism on local development. Following that, some of the most commonly used models for assessing the impacts of tourism on local development are presented and critiqued. Finally, an alternative model for assessing the socio-cultural, economic and environmental impacts of tourism clusters in a systemic way is proposed.

\section{THE TOURISM CluSTER AND THE LOCAL BASE}

The interaction of the consumption of the tourism product with its local base is one of the main characteristics of the activity, showing the fundamental role it plays in the strategies for local development. In most economic activities, it is the product that reaches the consumer, but when it comes to tourism, it is the opposite in that the consumer seeks for tourism services. Because of this characteristic, tourism has a heavy impact on local development. From this perspective, tourism and local development are interconnected because they take place if the regional socio-cultural and environmental characteristics are respected where the activity takes place.

\section{The Concept of Local Development}

The central idea of development includes a concept net made up of evolution, inclusion, participation, solidarity, production and competitiveness, which are mutually strengthened or directly opposed to movements of concentration, competition, exclusion, poverty and imbalance, amongst other things.

Evolution and interaction are the focal points of the concept of development, a set of coordinated participation processes for continuously improved discussion and increased planning capability and the ability to gather economic, social and environmental resources in the short and long term, whenever possible, owing to joint strategies that otherwise depend on arbitration and conciliation (OCDE, 2001).

The local development concept also includes to complementary ideas related to territory. One of them refers to a concrete and delimited space, which is linked to the idea of constancy and inertia, and 
can be identified as a limited area such as a municipality, micro-region etc. The other is the abstract space of social relationships and indicates movement and interaction between social groups that either cooperate or organize opposition to accommodate their common interests (Fischer, 2002). The idea of movement and interaction can be witnessed for as long as the territory has to take the interdependence between nature and its use into consideration, including human actions, i.e. work and politics (Santos, 1999).

Three elements of local development that stem from tourism are: society, the environment and the economy, which are integrated and mutually strengthened in a context where social and cultural diversity, as well as productive differences, should be used as resources to generate changes and local development.

Tourism differs from other productive activities in that it is a product that can only be consumed in loco, thereby stimulating the development of other economic activities (entertainment, trade, transport, lodgings, travel agencies, crafts, supporting services and amenities) in addition to the development of infrastructure (roads, airports, sanitation, energy, etc.) depending on the cultural and environmental sustainability and the generation of income and creation of local jobs.

\section{The Tourism Cluster Concept}

The concept of cluster is adopted to the specific characteristics of tourism activity, whose product is linked to its local base and to the joint action of an agglomerate of enterprises involved in the region's tourism product.

Porter defined agglomeration as:

...a geographical assembly concentrating inter-related enterprises, correlated institutions in a determined area linked to common and complementary elements. The geographical scope varies from a single town or state to the whole country or even a net of neighboring countries. The agglomerations assume diverse ways, depending on their deepness and sophistication, but most of them include enterprises of products and final services, specialized input suppliers, components, equipment and services, financial institutions, enterprises and correlated sectors. The agglomerations generally also include companies up and down in the supply chain, producers of complementary products, suppliers of specialized infrastructure, governmental institutions and others, devoted to specialized training, education, information, research and technical support (such as universities, study centers and workers on vocational training), and standardization agencies. The governmental institutions with main influence over the agglomeration would be one of its members. Finally, many agglomerates include commercial and other private associations which support its members. (Porter, 1999, p. 211-212)

Furthermore, there are other relevant characteristics, such as: information exchange between companies, institutions and individuals who are part of the cluster, the existence of a diversity of institutional infrastructure to support activities, socio-cultural identity, collective competitive advantages, the implementation of strategic actions among agents and the simultaneous organization of competition and cooperation relations among agents.

To Zacarelli (2004, p. 200), a complete cluster must include some other technology-related characteristics as well as characteristics related to competitiveness, environmental and cultural sustainability, quality of life and synergy as a result of systemic relations. The variables presented, Porter adds: the habit of reusing recyclable materials or sub-products; intense competition among cluster actors and from them to other clusters; similar technological pattern among enterprises; society culture adapted to cluster activities; high correlation and synergy among activities, agents and widening benefits concerning quality of living. 
The concept of cluster developed in this article is very similar to the joint concepts of Porter and Zacarelli, as the variables of attractiveness, competitiveness, economic and cultural sustainability and quality of life are the ones that make one tourism cluster different from the others.

The tourism cluster concept (adapted by Montfort from the Porter Agglomeration Concept):

A complex group of different elements, including services carried out by tourism companies or business (lodging, restoration, travel agencies, aquatic and theme parks, etc...); richness provided by tourist holiday experiences; multidimensional gathering of interrelated companies and industries; communication and transportation infrastructures; complementary activities (commercial allotment, holiday traditions, etc.); supporting services (formation and information, etc); and natural resources and institutional policies. (Montfort, 2000, p. 46)

While Montfort highlights a cluster as characteristics and components, Beni highlights the cohesion between agents and cooperation by creating company nets when defining cluster thus:

Tourism cluster is a group of highlighted tourism attractions within a limited geographic space provided with high quality equipment and services, social and political cohesion, linkage between productive chain and associative culture, and excellent management in company nets that bring about comparative and competitive strategic advantages. (Beni, 2003, p. 74)

The relations between enterprises and institutions and a tourism cluster can be understood in two ways (Rodrigues, 2001, p. 307):

Horizontal - by the creation of strategic alliances, where agreements can be of two kinds: on one side, the agreements between enterprises that have the same principal activity, i.e. among enterprises that deal with lodging, entertainment, transport and catering. On the other side, the agreements between enterprises working with the same group of customer satisfaction, but offering different product components to the customers (tourism service);

Vertical - by the creation of strategic nets, where there is the establishment of a unilateral suppliercustomer relation among the partners in such a way that the object activities of the agreement are fulfilled by one of the parts, which gives its output to the other in exchange for a payment.

In this article, we develop the concept that a tourism cluster is a group of companies and institutions bound up to a tourism product or group of products. Such companies and institutions are spatially concentrated and have vertical (within the tourism productive chain) and horizontal relationships (involving factor, jurisdiction and information exchange between similar agents dealing with a tourism product offer). They show an intern configuration that generally includes: a) a set of tourist attractions that draw non-resident attention; b) the concentration of tourism service companies: restaurants, accommodation, transport services, crafts, travel agencies etc.; c) sectors providing support to tourism services; d) suitable and low-cost infrastructure (roads, energy, sanitation, health services, etc.); e) companies and institutions that provide specialized qualification, information and financial capital; f) intern agents organized into class associations; g) government agencies and other regulating bodies that impact tourism agglomerations.

The advantages of cooperation nets in tourism activities allow for the effective exploitation of the collective efficiencies and/or the development of external companies from the enterprises (entrepreneurial cooperation, work productive specialization, collective infrastructure, service specialization etc.) and also makes it possible to benefit from the increased ability to negotiate collectively with suppliers of inputs and components. In addition to these advantages, cooperation nets facilitate the development of new models, production processes and organization, the exchange of technical and market information, consortiums for buying and selling goods and services, as well as joint marketing campaigns. Interaction and synergy arising from joint actions have competitive advantages over the isolated actions of companies (Nordin, 2003, p. 19). 
Although collaboration is a cluster-supporting basis, competition is performed vigorously. Even when cooperation is the cluster's main element, rivalry is also necessary for its development and survival. Without competition, companies are doomed to be unsuccessful, especially when it comes to the dynamic innovation process.

Due to the characteristics of the tourism cluster, local development programs consider it as a local strategy for combating regional disparities and social inequality. Porter (1999, p. 230) emphasizes that tourism does not depend only on the appeal of the main attraction (beaches or historical sites), but also on the comfort and service of hotels, restaurants, souvenir shops, airports, other modes of transport and so on. As the example shows, the parts of the agglomerate are generally effectively dependent on each other. A bad performance of one may compromise the success of the others.

Figure 1: Tourism Cluster Representation

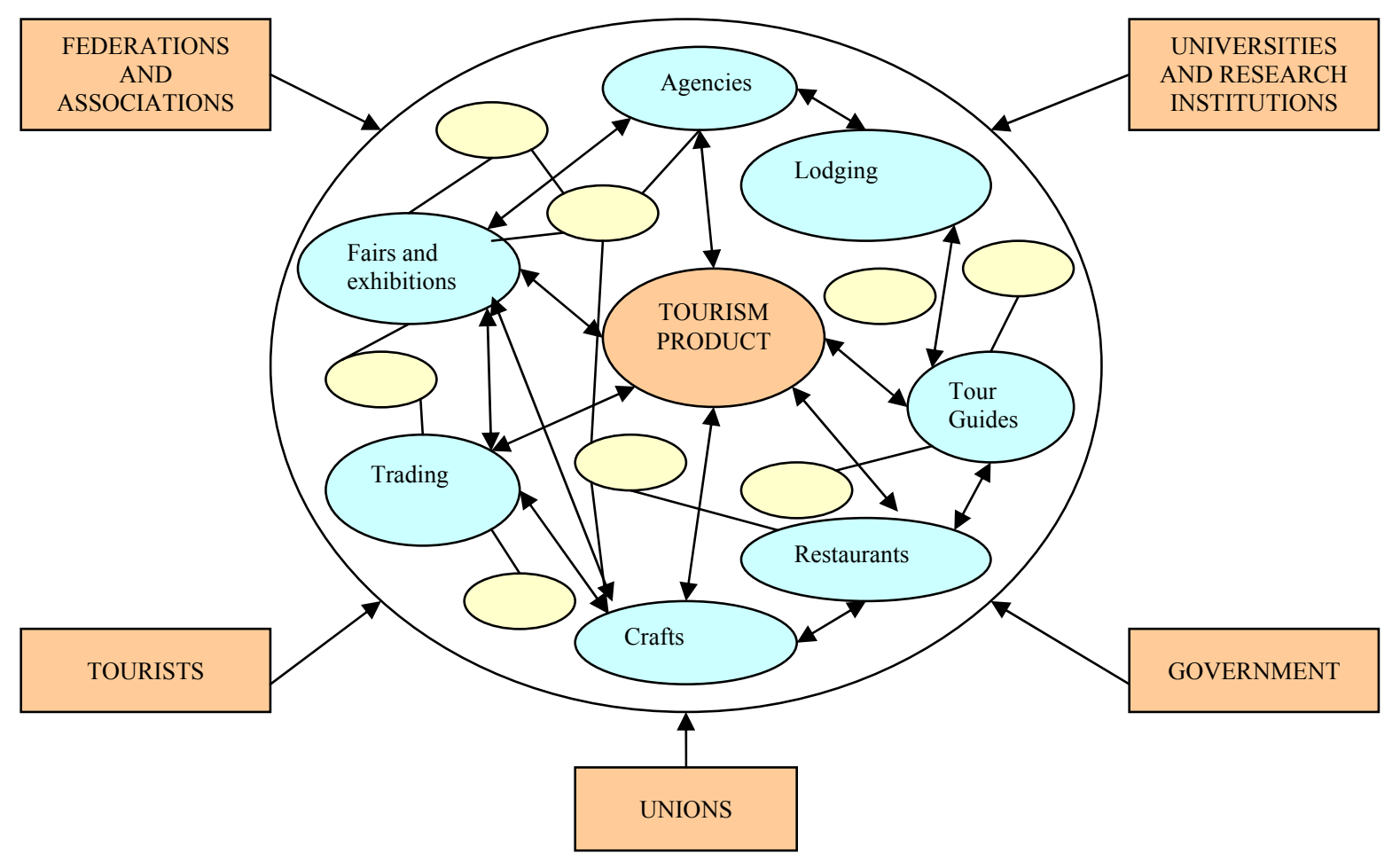

Source: supplied by the authors

Not all regions are adequately equipped in the same way to develop tourism activities. A region that is suitable for the development of tourism should have cultural, physical-natural and social characteristics that define its identity, accessibility to infrastructure, supra-structure (accommodation, restaurants., transport, etc.) to guarantee high quality tourism, strategic location near places where tourists come from, enough tourist attractions to draw tourists and sustainable economic activity. There should also be good tourism marketing strategies in order to divulge an attractive, unique and competitive image of its tourism product (Smith, 1989). However, the economic, social, environmental and cultural sustainability of the tourism cluster will only occur if the tourism product is based on public policies and strategic planning to determine its conditions for sustainability and multi-scale insertion (regional, domestic and global). 


\section{TOURISM CLUSTER SUSTAINABILITY}

The function of tourism causes direct impacts that affect both the territorial system and the production of tourism itself. The environmental spoiling of a beach does not mean only the deterioration of the territorial system but also competitiveness of the function of tourism in the region. (Ivars, 2004, p. 25-26).

Sustainability is a fundamental concept when reassessing the role of tourism in contemporary society. The World Tourism Organization defines sustainable tourism in this way:

Sustainable tourism is understood as the kind that satisfies the present needs of tourists as well as preserving the destination regions while incrementing future opportunities. It has to be conceived in a way to guide management of all available resources in order to meet economic, social and aesthetic demands, maintaining cultural integrity of essential ecological processes, biological diversity and life supporting systems. (OMT, 1998, p. 21).

The local development model based on sustainable tourism involves very complex relationships and can only be accomplished if the dimension reality of a certain region or territory is taken into consideration. Ruschmann (2001) emphasizes the need to consider the following dimensions when seeking to plan sustainable local development:

. Ecological and environmental sustainability: this refers to a physical basis development process that aims to preserve and use rationally the natural resources incorporated into tourism activities, as well as supporting capacity of the associated ecosystem to absorb or recover from anthropocentric aggressions.

Economic sustainability: this is the search for economic growth/development through the efficient allocation and management of resources and constant public and private investments to guarantee not only profitability at the micro-economic level, but also economic efficacy at the macro-social level in the present and future.

Socio-cultural sustainability: this is the need to maintain cultural diversity, values and practices currently existing in a region and building individual citizenship and complete social integration within a culture comprising rights and duties.

. Political-institutional sustainability: strengthening democratic mechanisms aimed at designing and implementing public policies, institutional arrangements and political-social representative organisms that have already taken sustainable criteria into consideration.

\section{TOURISM CluSTER SYSTEMIC PRODUCTIVITY}

The agents of the tourism cluster develop dense interaction, cooperative and competitive relationships such as: company (with suppliers, customers and competitors), meso-institution (with public and private institutions and representatives from civilian society), macro-institution (with macro-economic strategies and policies) and socio-cultural structure (social actor capability to formulate views and strategies for sustainable development).

The conjunction of territorial, institutional and entrepreneurial joints and their respective competitive advantages are what will result from the joint and global competitiveness of a tourism cluster.

[...] tourism competitiveness is the agent's capacity to interfere in a country, region or zone of tourism activity to reach their targets above the average of the 'sector' in a sustained and 
sustainable way, which can be reached through financially profitable concession above the average in the entrepreneurial field, and social and environmental gain as a consequence of the intervention of organizations and public institutions, in addition to obtaining maximum tourist satisfaction. Thus, the ultimate objective of competitiveness is to fulfill as best as possible the expectations of all the agents that take part in the activity of tourism. (Silva, 2004, p. 374)

Systemic cluster competitiveness (Altenburg, Gillegrand \& Stamer, 1998) comprises four levels of net relationships:

- Meta - comprising socio-cultural factors that define the articulating ability of social actors to formulate strategies and policies demanded by local society.

- Macro - macroeconomic strategies and stability determined by policies: fiscal, monetary, foreign exchange, commercial and competition policies.

. Meso - supporting structures that facilitate interaction and cooperation among companies (suppliers, customers and competitors), R\&D institutions, financial supports institutions, support and disclosure institutions (marketing, exports, fairs, etc.), labor training and training institutions and infrastructure ( transport, communications and energy).

- Micro - the capability of a company or company net to be competitive by offering goods and services that optimize cost efficiency relationships, quality and variety and the capability to respond to new market opportunities and changes.

Figure 2: Tourism Cluster Systemic Competitiveness Levels

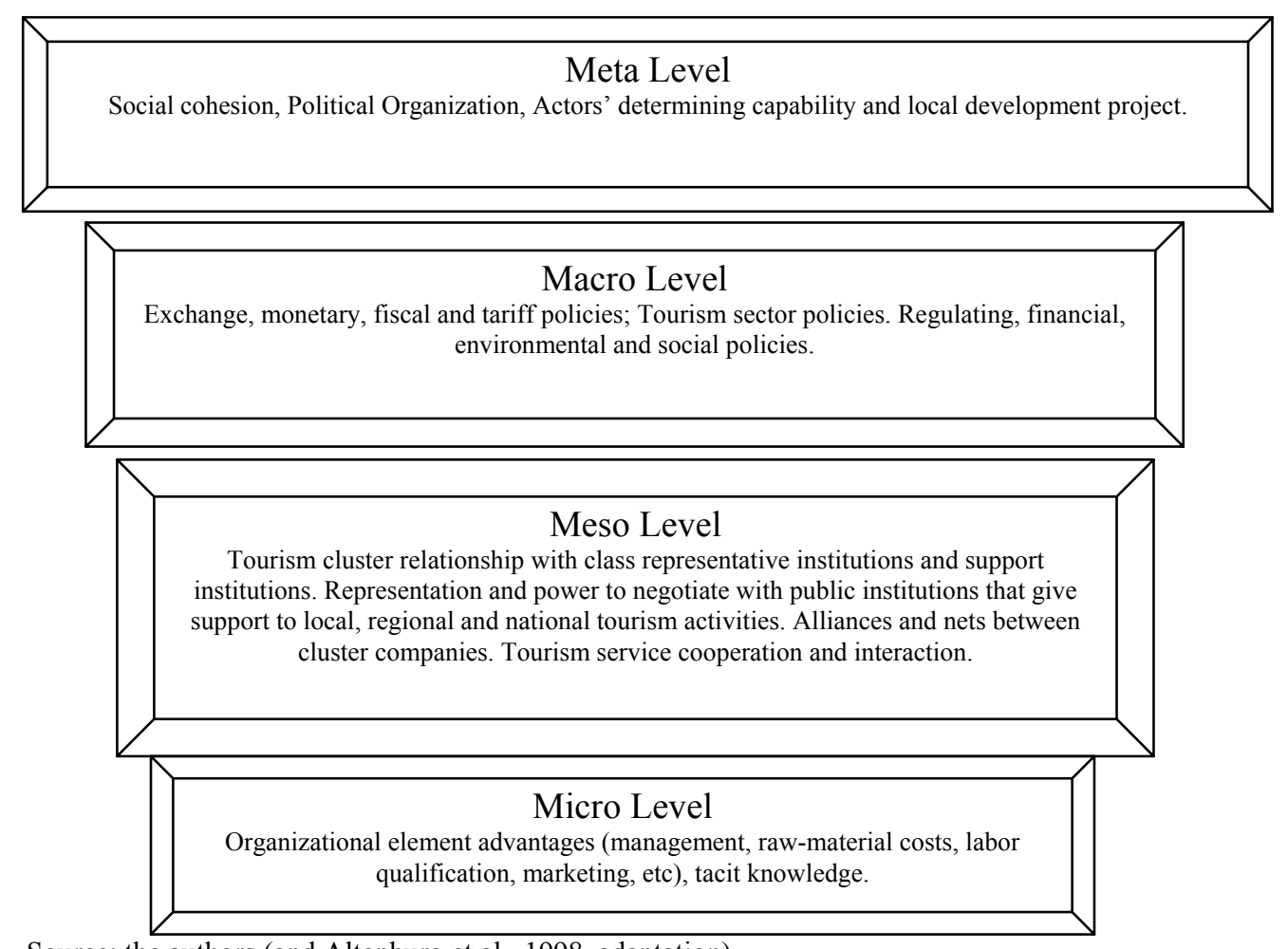

Source: the authors (and Altenburg et al., 1998, adaptation). 


\section{MOST COMMONLY USED METHOdologies tO ASSESS THE IMPACT OF TOURISM ON LOCAL DEVELOPMENT}

Since 1950, the United Nations Organization (UN) has maintained a standard system for measuring economic activity comprising a consolidated macroeconomic information system called the National Account System (NAS) which is currently used by all UN members. The NAS standardizes concepts, computation methodologies, statistics and information systems, thereby providing the country, region and sector with temporal economic results for comparison. Nevertheless, as the NAS is an aggregate information system, it is not suitable for carrying out sector analysis on specific activities such as tourism, health, education, agro-industry and other economic segments involving multi-sector activities.

During the conference that took place in Ottawa in 1991, the World Tourism Organization (WTO) proposed an accounts system specially aimed at tourism named the Tourism Satellite Account (TSA), which is compatible with the concepts, theoretical references and measuring methods of the NAS. Some countries, including Brazil, are structured to the TSA. Although such information is strategic for domestic planning, it is not sufficiently disaggregated at the regional level and does not have a temporal series that permits its use for local development planning. Therefore, there is an information and methodology gap in the assessment of the impact of tourism on local development.

According to Silva (2004, p. 267), tourism is a phenomenon defined from the viewpoint of demand, although most of the general economic classifications of activities are established from the viewpoint of the offer of products and services and the characterization of production processes. As a result, some adaptations of these classifications are necessary to describe and measure suitably and usefully, the economic incidence of tourism. To these methodological difficulties may be added the fact that, so far, the national experience in qualifying tourism from the view of demand has been rare. It is difficult, therefore, to identify accurately the statistic criteria that can be used on a universal basis.

Simultaneously, the WTO has been developing methodologies and objectives to create environmental system indicators for the sustainability of tourism. However, few countries and regions produce systematic, standardized and disaggregated indicators that are capable of measuring positive and negative effects on the environment, society, the economy and culture.

Great efforts have also been made to develop planning techniques. Inventories and the implantation of tourism centers are currently the best-known tourism planning techniques: tourism resource inventories, tourism zoning, tourism center implantation, tourism product and the integration of infrastructure, creation of tourism circuits and itineraries, spatial distribution of demand and costbenefit analysis, plus others.

There has been little progress in terms of developing methodologies to assess the impact of tourism quantitatively and qualitatively. The quantitative models of the economic impact are the most commonly used, mainly the Keynesian job and income multiplier model and those that measure the impact of tourism on the balance of payments of a country or region. Among social impact measuring models, the Human Development Index may be highlighted - the HDI, proposed and developed by the $\mathrm{UN}$, aims to measure the welfare and quality of life of the local population.

Another methodology used for territorial planning and organization in tourism is the Cargo Capacity. This methodology measures how much a destination space can be used without negative effects on the region's natural resources, the community and the economy without reducing tourist satisfaction.

Since the early nineties, concern for assessing the role of tourism as a strategy for improving territorial development has greatly increased. The disorganized growth of tourism can cause many 
kinds of problems for the local population, in addition to environmental damage, the destruction of cultural and historical heritage, and even the destruction of the potential of local tourism itself.

For this reason, the WTO has added the planning and assessment of the development of local tourism to its agenda by preparing "Agenda 21 for the Travel \& Tourism Industry" in an attempt to establish norms and procedures to prompt governmental and non-governmental organizations, as well as travel and tourism sector agents, to consider sustainable development as a central issue in political decision-making, planning and management processes. At the same time, new criteria and methodologies are being proposed to replace current technical procedures for evaluating the impact of tourism on local development. International institutions involved in tourism activities, as well as planning institutions from countries whose potential for development is based on tourism, are developing new methodologies for systemic and integrated assessment of economic, socio-cultural, environmental and political-institutional factor relations. To accomplish this objective, following an assessment methodology to measure the impact of tourism on local development is proposed.

\section{Evaluation of the Impact of Tourism on local Development: a Proposal for a SYSTEMIC MODEL}

Theoretical parameters and conceptual models of the impact of tourism on local development show gaps that only recently have been filled by researchers, universities and local research institutions. Most of the research has prioritized the microeconomic scale and more recently has been referred to as priority in matters of environmental sustainability.

This chapter outlines an alternative proposal for assessing the impact of tourism on local development. This model is based on the concept of tourism clusters and aims to assess the impact of a tourism product, or set of products, on economic, social, environmental and cultural competitiveness and sustainability in a given region. Concept and typology form its theoretic basis (Mytelka \& Farinelli, 2000; Porter, 1999) by adapting and integrating systemic competitiveness concepts (Altenburg et al., 1998) and the determinants of the competitive advantages of Porter's Diamond Model (1999). This model also used the concepts of sustainability on economic, social, cultural and environmental political dimensions (Ruschmann, 2001). 


\section{Schematized Presentation of a Systemic Model to Measure the Impact of Tourism Activity on Local Development}

Figure 3: Cluster Model for the Impact of Tourism on Local Development: Competitiveness and Sustainability

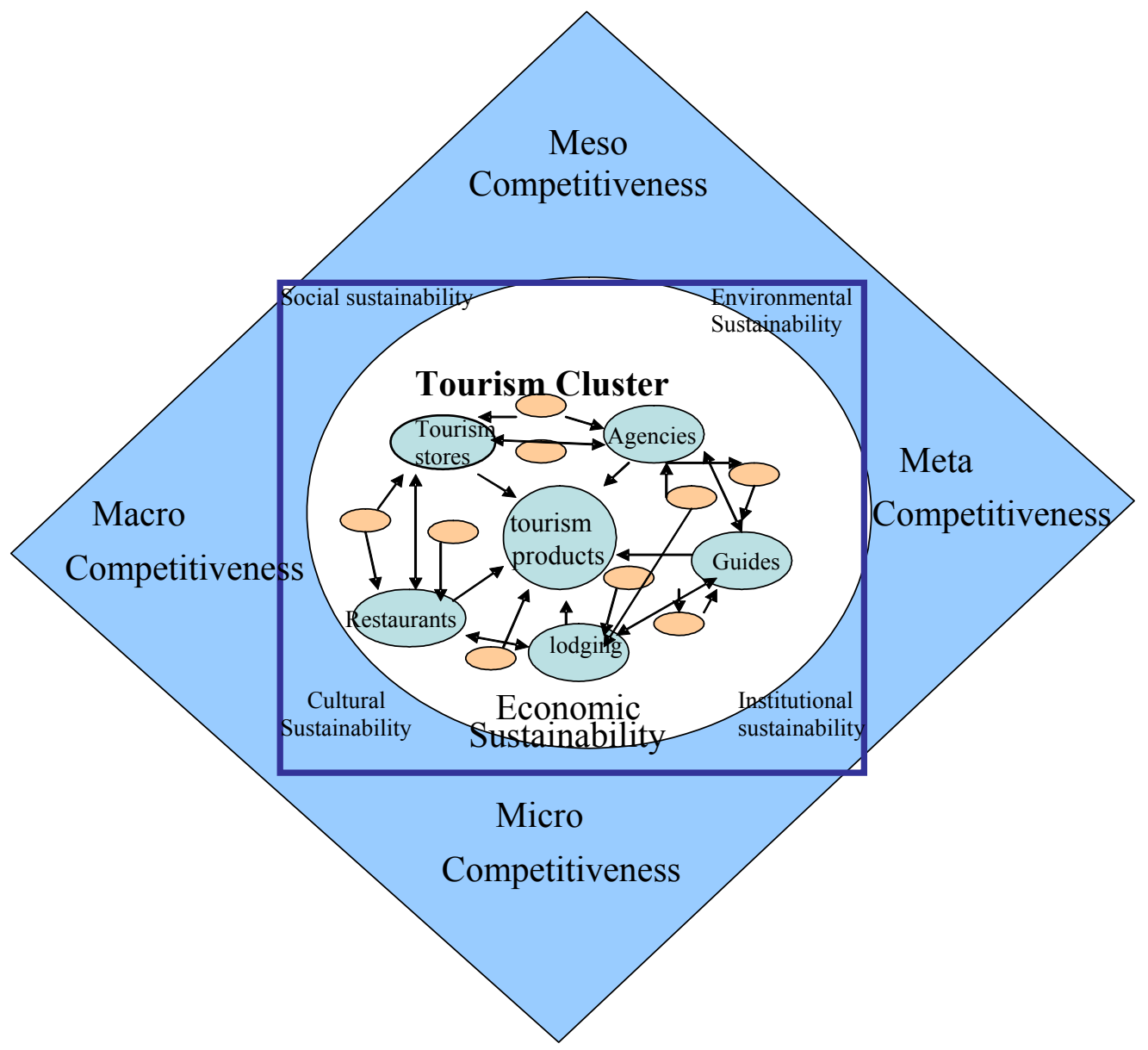

Methodology developed by the author

In order to carry out a comparative analysis, the method to be used should be generic. It should also take into account all the actors in the tourism clusters, their relationships and the factors that induce competitiveness at different levels (meta, macro, meso and micro), sustainability (economic, social, environmental, cultural and political-institutional) which may be applied to all types of tourism clusters and therefore be used for regional and temporal comparisons.

Similarly, for interrelation analysis between actors and competitiveness and sustainability inducing factors in each cluster, the use of techniques that can be applied to different situations is proposed (Cunha et al., 2004).

\section{The Steps of Development and the Application of the Method}

\section{Step 1 - Identifying and characterizing a tourism cluster}

To delimitate a tourism cluster, it is suggested that the following aspects should be identified:

. the product or tourism product and their attractiveness and potential for diversity; 
. set of enterprises that potentially compose the structure;

- support supra-structure to the tourism product on offer (restaurants, hotels, travel agencies, commerce, crafts, tourism support service etc.);

supportive infrastructure (roads, sanitation, energy, communication etc.);

institutional supporting services (governmental institutions, enterprises and workers associations, workers training centers, promoting institutions etc.).

From the identification of the components and their relations and tourism cluster spatial delimitation, it is suggested that the following stages should be followed to identify cluster characteristics and diversity in analyses:

. sector diagnosis, at the internal and external levels;

- definition of the general objectives that mean the generic cluster objective, which is to improve competitiveness and sustainability;

strategies or generic actions should be drawn to achieve objectives.

Step 2 - Identifying the main actors or cluster constitutive elements organized as a net-work?:

. identify and assess the factors that induce competitiveness at different levels (meta, macro, meso and micro);

- identify and assess the factors that induce sustainability at different levels (economic, social, environmental, cultural and political-institutional);

- analyze the interrelation between the factors that induce competitiveness and sustainability and the main actors in the cluster;

- establish and analyze institutional profiles that characterize the cluster actors organized into elements and roles of each institution.

Step 3: Field survey and crossed impact matrix design: comprises a double-entry matrix design that lists local agents and actors on one axis and sub-factors and variables that impact on local development on the other axis:

. Each factor that induces competitiveness and sustainability is divided into a series of sub-factors and variables to which a relative weight considers their degree of influence on the local development process;

. Factor, sub-factor and variable impact intensity are assessed by way of grades assigned at interviews with the cluster actors (companies, public and private institutions and community representatives);

. Each person interviewed will assess the influence of a given sub-factor or variable over local development in a very favorable $(+2)$, favorable $(+1)$, neutral $(0)$, unfavorable $(-1)$ or very unfavorable (-2) way;

- The grade given will be pondered by a relative weight previously assigned to each sub-factor;

- The sum of grades given each sub-factor will result in relative grades of each general inducing factor.

\section{Step 4: Information statistic methodology - main component analysis}

In order to select and classify into hierarchies the variables that mostly affect the systemic competitiveness and sustainability of tourism clusters and their impact on local development, a 
multivariable statistical analysis known as the Main Component Analysis is used. This technique permits a reduction of the characteristic variables of competitiveness and sustainability to a small number of explanatory indexes (main components) by means of linear combinations of the original variables. The main component analysis seeks a minimum number of linear combinations that can be used to explain the variable dispersions shown in the basic information matrix.

Step 5: Classification into hierarchies of the inducing factors that positively or negatively affect competitiveness and sustainability of the tourism cluster.

Step 6: The research results will be evaluated through a workshop with the main cluster actors. At the workshop, the results will be presented for appreciation and debate by the actors, who should indicate possible suggestions to raise the competitive potential of the cluster, reducing negative impacts concerning economic, social, environmental and cultural terms.

Step 7: Preparation of a final report to present the main results of the research.

\section{Main Results and Products Generated by the Model}

The aim of the proposed model is to evaluate the impact of tourism on local development, all the while taking into account the conceptual cluster model adapted to the characteristics and diversities of the tourism sector. Three fundamental focuses are used to evaluate the impacts, resulting in different products that can be presented and used separately, albeit in a complementary way. The main contribution of the proposed model is its systemic focus, taking into account and classifying the variable of competitiveness and sustainability, which influence local development either positively or negatively.

The first focus is to define, identify and delimitate the tourism cluster. The products generated by this level of information are of extreme importance to the analyses of agglomerations and to evaluate the degree of tourism activity clustering, the role and importance of each actor and agent in the cluster, the relations and their intensity among the actors, the degree of complementation among the internal cluster activities, in addition to the gaps and lack of activities in the cluster. The final product of this phase is the mapping of the tourism cluster, including the actors, the knots and the fluxes. The externally demanded activities will also be indicated, which can be offered internally, and also the evaluation of the potential for development of the intra-cluster.

The competitiveness of the tourism cluster seen through the systemic competitiveness hybrid model (at the meta, meso, macro and micro levels) and Porter's determinants of competitive advantage will lead to the identification of the factors of competitive advantage, which reveal fragilities concerning competitiveness. The identification of the competitive potentials and fragilities at various levels and with the different actors is shown to be a basic tool for planning and defining public policies and the direction of strategies of organizations. The product generated from all this information allows for the creation of a two-entrance matrix for the identification and qualification of the competitive variables by the cluster agents and actors on a positive and negative scale.

The theoretical basis of the third focus is the sustainability model evaluated in its economic, social, environmental and cultural aspects. The contribution of each actor concerning sustainability in different aspects will also be identified. From all this information, a two-entrance matrix will be generated to identify and qualify the contribution of each agent and actors concerning the economic, environmental, social and cultural sustainability on a positive and negative scale.

Finally, the Systemic Model for measuring the impact of the tourism cluster on local development will be obtained through the statistical method of the analyses of the main components, which will result in a matrix that classifies and quantifies the contribution of different factors to local development. The result presented by the model is the basis for decisions taken by local agents, the planning system and the formulators of public policy, offering synthetic indicators of the systemic 
sustainability and competitiveness of the tourism cluster as a whole, as well as detailed and crossed information of agents and their potentialities and fragilities of strategic variables.

\section{The Advantages and Limitations of the Model}

One of the aims of the planning and development institutions for domestic and international tourism is to establish models to assess the impact of tourism activity on local development (economic, social, cultural and environmental) that provide adequate and realistic results that adhere to the concepts of homogenizing scientific criteria and standardizing statistics, thereby allowing for a comparison between spatial, sector and temporal indicators.

The model proposed in this article is in intended to meet the aforementioned objectives through a holistic, multidisciplinary and multi-sector view of local development and a systemic approach to systemic competitiveness, social equity and sustainability concepts. The application of the model does not require a pre-existing data base as it is based on primary information provided by research made by local agents, permitting cluster agents with perception and comprehension. The application of this methodology takes a relatively short time at relatively low cost. Besides these two advantages, this model has several other advantages over other methodologies as it shows results that can guide system agents strategically when it comes to public policies and decision-making processes for competitiveness, competition, cooperation and sustainability strategies for private and public companies and institutions. The information provided by the application of this model also allows us to:

- analyze economic, social, cultural, environmental and political-institutional factors systemically;

. map the intensity flow relationships between the internal agents of the tourism cluster (relationship with competitors, suppliers, service providers, support activities, government institutions, class associations, education and labor training institutions);

identify and classify into hierarchies the relationship of internal cluster agents with regional, domestic and international agents, as well as identify and assess the extent of cluster complementariness and external dependence;

- assess the maturity of the tourism cluster and factors that obstruct or support local development (supporting policies, cohesion or conflict among agents, interaction, competition, tacit knowledge disclosure, information system, infrastructure, supra-structures etc.).

As main model limitations, regional and temporal cut is in evidence, i.e. the model is static and its time and space comparisons depend on its reuse. Furthermore, this model only allows for the classification of those variables that are responsible for tourism cluster competitiveness and sustainability and for its negative and positive impacts on local development.

\section{CONCLUSION}

In the last fifty years, tourism has been one of the activities with the highest expansion potentials in the world. It plays an important role as a local development strategy due to its potential for growth and for being a product that can only be consumed in loco. Although it has a relevant potential for development and plays an important role in defining public interventionist policies, there has been little progress in terms of study, research and models for measuring the impact of tourism on local development.

The spatial expansion of tourism and the growing diversification of this activity in the world at the same time creates opportunities for countries, regions and communities to seek to bring about their 
development but also brings damaging effects when decomposing and recomposing spaces, deteriorates and weakens the environment, destroys and builds productive social relationships that already existed and breaks local diversities and cultures, incorporating alien consumer patterns and habits.

One of the challenges for government agents in charge of elaborating and implementing development policies for tourism activities is to build a model of sustained development with competitiveness, sustainability and social justice.

The focus of the cluster analyses is adapted to the characteristics of tourism activity as it is based on the analyses of agglomerations, functional complementary, cooperative relationships and competition among actors. Otherwise, the traditional cluster analyses are not clear when the objective is to evaluate local impacts concerning competitiveness, sustainability and social justice.

This article is intended to contribute a measuring model for the impact of tourism clusters on local development, aggregating to Porter's agglomeration analyses, competitiveness concepts at different levels and the concepts of environmental, social and cultural sustainability.

The result obtained from the application of the impact measurement model are tools for the reconciliation of environmental preservation, social justice and the conservation of culture and diversity, therefore contributing an advancement for the implementation of more sustainable tourism cluster development models, as it is a tool that allows for diagnosis, evaluation and prevention of real and potential impacts that come with the growth of tourism.

The final objective of the model is to generate data that strategically guide agents in charge of public policies, as well as enterprises and public and private institutions in their competitiveness, competition, cooperation and sustainability strategies.

As the main limitation of the proposed model is its temporal and regional focus, this is a static model, and comparisons in time or space depend on its reapplication.

\section{REFERENCES}

Altenburg, T., Gillegrand, W., \& Stamer, J. M. (1998). Building system competitivenss. Berlim: German Development Institute - GDI.

Beni, M. C. (2003). Globalização do turismo: megatendências do setor e a realidade brasileira. São Paulo: Aleph.

Cunha, S. K., Cunha, K. C., Souza, A., \& Cunha, J. C. (2004). Grau de clusterização da indústria de painéis de madeira da região de Palmas - PR.. In: Simpósio de Gestão da Inovação Tecnológica. Tecnologia e Desenvolvimento: Desafios e Caminhos Para Uma Nova Sociedade, (pp. 119-134). Curitiba: PGT/USP.

Fischer, T. (2002). Poderes locais, desenvolvimento e gestão. Introdução a uma agenda. In: Ficher, T. (org). Gestão do desenvolvimento e poderes locais: marcos teóricos e avaliação, (pp. 12-32). Salvador, BA: Casa da Qualidade.

Ivars, J.A. (2003). Planificación turística de los espacios regionales en España. (pp. 25-26.). Madrid: Síntesis.

Mytelka, L. E., \& Farinelli, F. (2004). From local clusters to innovation system. In: System of innovation and development: evidence from Brazil. (pp. 249-272). Cheltenhan, UK, Northampton, MA, USA: Edward Elgar. 
Mytelka, L. E., \& Farinelli, F. (2000). Local clusters, innovation systems and sustained competitiveness In: Arranjos produtivos locais e as novas políticas de desenvolvimento industrial e tecnológico. Nota Técnica n. 5. Estudos Temáticos. IE/UFRJ. Rio de Janeiro. p. 19. Retrieved March 16, 2002, from http:// www.ie.ufrj.br/gei/gil.shml.

Monfort, M., V. M. (2000). Competitividad y factores críticos de éxito en la "hotelería de litoral": experiencia de los destinos turísticos Benidorm y Peñiscola (Doctoral Dissertation, Universidad de Valência, Espanha, 2000). Retrieved September 2, 2003, from http:// www.cervantes.com/fichaobra.htlm?Ret=2619.

Nordin S. (2003). Tourism clustering and innovation: path to economic growth and development. european tourism research institute. MID - Sweden University. Osternsund, Sweden, p.19. Retrieved May 4, 2004, from http:// www.etour.se/dounload.

Organization de Cooperation et de Development Économiques (OCDE). (2001). Stratégies de développement durable (pp.15-33). Paris, Author. Retrieved August 29, 2003, from http://www.oecd.org/dataoecd/34/102669958.pdf.

Organización Mundial del Turism (OMT). (1998). Guide for local authorities on developing sustainable tourism. (p.21). A tourism abd environment publication. Madrid: Author. Retrieved 2004, from http://www.would-tourism.org/publications/PR 1016-1.html.

Porter, M. E. (1999). Competição. (2nd ed.). Rio de Janeiro: Campus.

Rodrigues, A. B. (Org). (2001). Turismo rural. São Paulo: Contexto.

Ruschmann, D. V. M. (2001). Turismo e planejamento sustentável: a proteção do meio ambiente. (7th ed.). Campinas: Papirus.

Santos, M. A (1999). Natureza do espaço: técnica e tempo, razão e emoção. (4th ed.). São Paulo: Edusp.

Silva, J. A. S. (2004). Turismo, crescimento e desenvolvimento: uma análise urbano-regional baseada em Cluster. Tese de Doutorado, Faculdade de Filosofia, Letras e Ciências Humanas da Universidade de São Paulo. USP, São Paulo.

Silveira, M. A. T. (2002). Turismo, politicas de ordenamento territorial e desenvolvimento. Um foco no Estado do Paraná no contexto regional. Tese de Doutorado, Faculdade de Filosofia, Letras e Ciências Humanas da Universidade de São Paulo. USP, São Paulo.

Smith, S. (1989). Tourism analysis. A handbook. New York/London: Longman.

World Tourism Organization - WTO. Turismo y desarrollo local sostenible: elemento para un debate. In: Noticias Delnet - Centro Internacional de Formacion de la OIT. n. 24. 2004. Retrieved October 11, 2004, from http://www.world-tourism.org.

Zacarelli, S. B. (2004). Estratégia e sucesso nas empresas. (4th ed.). São Paulo: Saraiva. 